\title{
3D interactions with the growth hormone locus in cellular signalling and cancer-related pathways
}

\author{
Lekha Jain, Tayaza Fadason, William Schierding, Mark H Vickers, Justin M O'Sullivan and Jo K Perry \\ Liggins Institute, University of Auckland, Auckland, New Zealand \\ Correspondence should be addressed to J K Perry or J M O'Sullivan: j.perry@auckland.ac.nz or justin.osullivan@auckland.ac.nz
}

\begin{abstract}
Growth hormone $(\mathrm{GH})$ is a peptide hormone predominantly produced by the anterior pituitary and is essential for normal growth and metabolism. The GH locus contains five evolutionarily related genes under the control of an upstream locus control region that coordinates tissue-specific expression of these genes. Compromised GH signalling and genetic variation in these genes has been implicated in various disorders including cancer. We hypothesised that regulatory regions within the $G H$ locus coordinate expression of a gene network that extends the impact of the $\mathrm{GH}$ locus control region. We used the CoDeS3D algorithm to analyse 529 common single nucleotide polymorphisms (SNPs) across the GH locus. This algorithm identifies colocalised Hi-C and eQTL associations to determine which SNPs are associated with a change in gene expression at loci that physically interact within the nucleus. One hundred and eighty-one common SNPs were identified that interacted with 292 eGenes across 48 different tissues. One hundred and forty-five eGenes were regulated in trans. eGenes were found to be enriched in GH/GHR-related cellular signalling pathways including MAPK, PI3K-AKT-mTOR, ERBB and insulin signalling, suggesting that these pathways may be co-regulated with GH signalling. Enrichment was also observed in the Wnt and Hippo signalling pathways and in pathways associated with hepatocellular, colorectal, breast and non-small cell lung carcinoma. Thirty-three eQTL SNPs identified in our study were found to be of regulatory importance in a genome-wide Survey of Regulatory Elements reporter screen. Our data suggest that the $\mathrm{GH}$ locus functions as a complex regulatory region that coordinates expression of numerous genes in cis and trans, many of which may be involved in modulating $\mathrm{GH}$ function in normal and disease states.
\end{abstract}

Key Words
- growth hormone locus
- GH1
- genome
- chromosome capture
- cancer

\section{Introduction}

Growth hormone (GH) is a peptide hormone released in a pulsatile fashion from the anterior pituitary. GH is critical for mediating normal postnatal longitudinal growth in childhood and puberty and in regulating metabolism (Bonert \& Melmed 2017). Secretion of GH is positively modulated by GH releasing hormone (GHRH), ghrelin, and negatively by somatostatin. Insulin-like growth factor (IGF-1) is a key mediator of GH actions. Compromised GH/IGF-1 signalling is associated with several wellcharacterised growth disorders and is linked to an altered 
susceptibility to cancer, diabetes and cardiovascular disorders (Hannon et al. 2017, Guevara-Aguirre et al. 2018, Gadelha et al. 2019). In particular, altered GH expression has been linked to melanoma, breast, endometrial, liver and colorectal cancer by evidence from in vitro, animal and clinical studies (Chhabra et al. 2011, Brittain et al. 2017, Perry et al. 2017).

The GH gene cluster is located on the long arm of chromosome 17 (17q23) and is composed of five homologous genes, GH1 (also known as GH-N), GH2 (also known as $G H-V$ ) and chorionic somatomammotropin genes (CSH1, CSH2 and CSHL1) (Liao et al. 2018). Tissuespecific expression of the $G H$ locus genes is regulated by a locus control region which overlaps the $C D 79 B$ and $S C N 4 A$ genes that are located upstream of the GH1 gene. GH1 is expressed primarily in the pituitary and other extra-pituitary tissues, whereas the rest of the locus genes are expressed predominantly in the syncytiotrophoblast layer of the placenta (Su et al. 1997). Studies have demonstrated that coordinated regulation of $G H$ locus genes is mediated by complex chromatin looping and epigenetic mechanisms (Kimura et al. 2007, Ganguly et al. 2015, Ho et al. 2008, Tsai et al. 2016).

GH effects are mediated through activation of downstream signalling cascades following binding to the GH receptor (GHR) and through stimulation of secretion of secondary peptide mediator molecules, in particular, IGF-1 (Waters 2016, Bonert \& Melmed 2017, Dehkhoda et al. 2018). Key signalling pathways pertaining to GH-GHR signal transduction include JAK2 signalling via STATs (1, 3 and 5), the MAPK pathway, JNK pathway, mTOR (mammalian Target of Rapamycin) and PI3K pathway (Carter-Su et al. 2016, Lu et al. 2019). These signal transduction pathways mediate GH effects by altering gene transcription profiles, through direct stimulation of transcription and by modifying chromatin (Rotwein \& Chia 2010).

Enhancers and promoters are physically brought together to facilitate the regulation of gene expression by complex 3D mechanisms that are dependent on a multitude of factors (Sanyal et al. 2012, Schierding \& O'Sullivan 2015). This physical contact/interaction between enhancers and promoters can be captured by proximity ligation techniques such as Hi-C (LiebermanAiden et al. 2009, Eijsbouts et al. 2019, Kong \& Zhang 2019). A genomic variant associated with allele-specific changes in the expression of a gene is known as an expression quantitative trait locus (eQTL). Notably, the regulation of gene promoters can be mediated through both proximal and distal regulatory elements (cis and trans interactions, respectively), with the latter including interactions between different chromosomes (Gibcus \& Dekker 2013, Schierding et al. 2016). These interactions can associate with either higher (enhancer) or lower (insulator/silencer) expression.

As described above, coordinated regulation of $\mathrm{GH}$ locus genes is known to be mediated by complex chromatin looping (Kimura et al. 2007, Tsai et al. 2016). In light of recent studies which show regulation of gene networks by alteration of chromosomal interactions in the nucleus (Lanctôt et al. 2007), it is possible that some GH functions may be mediated by spatial interactions between regions of the $G H$ gene locus and distal loci. Changes in chromatin organisation, structure and interactions play a crucial role in the regulation of gene expression (Dekker et al. 2013, Schierding \& O'Sullivan 2015, Schierding et al. 2016, Fadason et al. 2017). Therefore, the study of polymorphisms related to genes in this axis could potentially lead to elucidation of novel regulatory networks involving genes associated with $\mathrm{GH} /$ IGF-1 axis function.

We hypothesised that regulatory regions within the $\mathrm{GH}$ locus coordinate expression of a gene network that extends the impact of the $G H$ locus control region. We integrated 3D genome organisation and tissue specific gene expression data to identify functional cis and trans spatial eQTLs that involved the $G H$ locus. We identified regions within the $G H$ locus that regulate multiple genes involved in key cellular signalling and cancer-related pathways, many of which are related to GH-related signalling pathways.

\section{Materials and methods}

\section{Mapping of SNPs across the GH locus}

We collated a list of common single nucleotide polymorphisms (SNPs) (dbSNP147; Minor allele frequency $\geq 1 \%$ ) located across the $G H$ gene locus including its control region (Chr17:62080000-61920000; GRCh37/hg19) (Supplementary data $1-a$, see section on supplementary materials given at the end of this article). SNP density across the $G H$ locus was calculated using a sliding window (500 bp window, 100 bp step size) in RStudio (Version 1.1.414).

Known enhancer sites across the $G H$ locus were obtained from GeneHancer (Fishilevich et al. 2017), which collates information from the ENCODE project (Dunham et al. 2012), Ensembl regulatory build (Zerbino et al. 2018) and FANTOM5atlas of active enhancers 


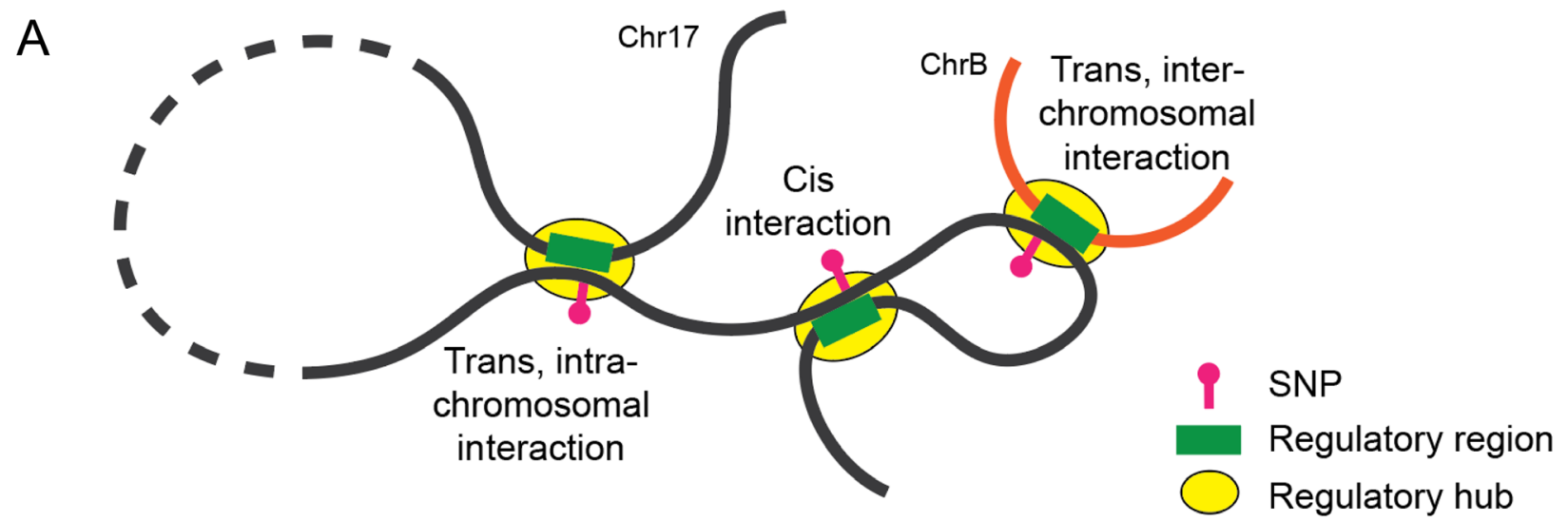

B

Chr17:

Chr17:

62080000
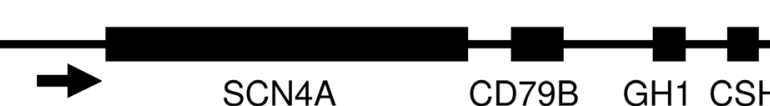

CD79B

$\mathrm{GH} 1 \mathrm{CSHL} 1 \quad \mathrm{CSH} 1$

1920000

LCR

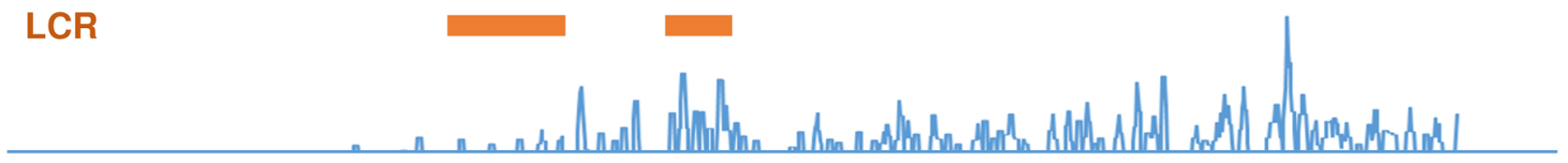

GH2 CSH2 TCAM1P

eGene frequency

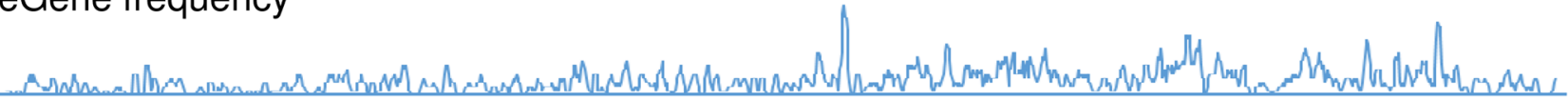
SNP density

Figure 1

(A) Schematic diagram representing the types of eQTL interactions. Cis interactions occur when a region containing a SNP physically contacts a nearby region/gene (<1 Mb away), whereas trans interactions occur between a SNP containing region and a distal region/gene (>1 Mb apart). These regions can either be located on the same chromosome (intra-chromosomal) or on different chromosomes (inter-chromosomal). (B) Pattern of eQTL regulatory interactions for common SNPs (sourced from dbSNP147) located across the GH gene locus (GRCh37/hg19- Chr17:62080000-61929000). Orange boxes indicate the approximate position of the locus control region (LCR). Tracks below show the density of the 529 common SNPs that were analysed across the region and the frequency of eGenes identified as being associated with those SNPs.

(Lizio et al. 2015). Topologically associating domains (TADs) within the seven cell lines (i.e. GM12878, HMEC, KBM7, HUVEC, IMR90, K562 and NHEK) were determined using the 3D Genome Browser at 1-kb resolution and Hi-C data from Rao et al. (2014).

\section{Identification of eQTLs within the $G H$ locus and their genome-wide targets}

GH locus SNPs were analysed using the CoDeS3D (Contextualize DevelopmentalSNPs using 3D Information) algorithm (GitHub, https://github.com/Genome3d/ codes3d-v1) (Fadason et al. 2017). CoDeS3D integrates genome spatial connectivity data (i.e. maps of loci that physically interact, captured by Hi-C (Rao et al. 2014)) and links it to eQTL data obtained from the GenotypeTissue Expression (GTEx) database (v7) (Ardlie et al. 2015).
These results were corrected for false discovery using the Benjamini-Hochberg correction procedure (Fadason et al. 2017). The CoDeS3D database was loaded with Hi-C data for GM12878, IMR90, HMEC, NHEK, K562, HUVEC and KBM7 human cell lines (Rao et al. 2014). Cis-eQTLs were defined as involving SNPs that were located $<1 \mathrm{Mb}$ from the affected gene (or eGene), whereas trans-eQTLs were defined as involving SNPs located $>1 \mathrm{Mb}$ from the affected eGene on the same chromosome or on a different chromosome (Fig. 1A) (Fadason et al. 2017).

\section{Pathway enrichment analyses}

To identify enrichment of eGenes within biological pathways, we analysed the eGenes set (identified by CoDeS3D) using g:ProfileR package in R (https://biit.cs.ut. ee/gprofiler/). The reference gene sets were from KEGG 
Table 1 Overview of connections in cis and trans identified by CoDeS3D.

\begin{tabular}{l}
\hline SNPs analysed \\
\hline 529
\end{tabular}

$\frac{\overline{\text { SNPs with eQTLs }}}{181}$

\begin{tabular}{c}
\hline eGenes \\
\hline 292 \\
\hline
\end{tabular}

$\frac{\text { Cis eGenes }}{32}$

(KEGG FTP Release 2019-09-30), Reactome (annotations: ensemble classes: 2019-10-2) and WikiPathways (20190910). An adjusted $P$ value $<0.05$ was significant following Benjamini-Hochberg correction for false discovery rate (FDR) (Raudvere et al. 2019).

\section{Data visualisation}

Figures were drawn in RStudio (Version 1.1.414) using the following packages/libraries:

Circlize (Gu et al. 2014), ggplot2 (Gómez-Rubio 2017) and magrittr (Bache \& Wickham 2016).

\section{Results}

\section{Common polymorphisms across the $\mathbf{G H}$ gene locus are associated with expression of multiple downstream genes}

We used CoDeS3D to analyse 529 common SNPs (dbSNP 147) across the GH locus (Chr17:62080000-61920000; GRCh37/hg19) and identify SNP-eGene pairs in which the SNP was associated with the eGene expression level (Fig. 1B and Supplementary data 1-a) (Fadason et al. 2017). This analysis identified 181 SNPs that interacted with 292 genes in 48 different tissues (Table 1 and Supplementary data 1-b). There were 2141 SNP-eGene associations (FDR <0.05, Benjamini-Hochberg correction) in cis ( $<1 \mathrm{Mb}$ distance between the SNP and eGene) and 708 associations in trans (where the SNP and eGene are $>1$ $\mathrm{Mb}$ apart or on different chromosomes).

We compared the distribution of the eQTL SNPeGene interaction frequency and query - SNP density across the selected region (Fig. 1B). Notably, the number of SNPs per 500 bp sliding window did not correlate $\left(R^{2}=0.1\right)$ with the number of functional eQTLeGene interactions (Supplementary Fig. 1). Thus, the identification of regions with functional eQTL-eGene interactions was not an artefact of regions of higher SNP density across the $G H$ locus. However, the number of ciseQTLs in each tissue correlated positively $\left(R^{2}=0.64\right)$ with the number of samples present in GTEx for the respective tissue (Supplementary Fig. 2). Notably, there are some tissues that are outliers in the correlations, including the pituitary, cerebellum, oesophagus, pancreas, breast and adipose tissues. Interestingly, most of these tissues

\begin{tabular}{c}
\hline Trans eGenes \\
\hline 260 \\
\hline
\end{tabular}

$\frac{\text { Cis connections }}{2141}$

have key functions that relate to GH action (Bartke 2011, Clasen et al. 2014, Duan et al. 2015, Tarnawski et al. 2015, Bonert \& Melmed 2017, Pekic et al. 2017).

Within the nucleus, chromosomes are arranged through a hierarchy of structures that include topologically associating domains (TADs). TADs are defined as regions where spatial contacts are enriched (Tang et al. 2015). To determine whether the observed SNP-eGene connections crossed TAD boundaries, a Hi-C heat map was generated at $1-\mathrm{kb}$ resolution using Hi-C data captured in the GM12878, HMEC, KBM7, HUVEC, IMR90, K562 and NHEK cell lines (Rao et al. 2014). The Hi-C analysis clearly showed that there were numerous SNP-eGene connections observed both within the individual TAD containing the $G H$ locus region and across the TAD boundaries (Fig. 2A and Supplementary Fig. 3). This is consistent with SNP-eGene connections not being limited to occurring within TADs (Ciabrelli \& Cavalli 2015, Ulianov et al. 2016, Chen et al. 2018). Connections were also observed with eGenes present on different chromosomes (Fig. 2B), consistent with the concept that physical interactions between two genomic regions are not restricted by proximity in linear distance.

As the SNPs which we used for our study were part of the $G H$ region (which consists of $S C N 4 A, C D 79 B$, GH1, CSHL1, CSH1, GH2, CSH2 and TCAM1P genes), we analysed whether there were any connections going back into these genes. SNPs $(n=73)$ located across the entire $G H$ region had connections with $C D 79 B$ in 16 tissues, one SNP with CSHL1, three SNPs with GH2 in pituitary tissue, 114 SNPs with CSH2 in three tissues and 173 SNPs with TCAM1P gene in 24 tissues. As the locus control region is critical for regulation of these genes, we focused on interactions in this region. Twenty-seven SNPs from across the $G H$ locus control region connected to $C D 79 B$ in 13 tissues, one SNP to CSHL1 and one SNP to GH2 in pituitary tissue, 19 SNPs to CSH2 in three tissues (testis, cerebellum and cerebellar hemisphere) and 33 SNPs to TCAM1P gene in 18 tissues (Supplementary data 1-b). This is consistent with Tsai et al. (2016) who used chromatin conformation capture (3C) data from human pituitary and placental tissues to demonstrate that the $G H$ locus control region regulates these genes (Tsai et al. 2016). Notably, we identified only a few eQTLs with CSHL1 and GH2 and no eQTLs with the GH1 gene, which may reflect https://jme.bioscientifica.com

https://doi.org/10.1530/JME-20-0010
(C) 2020 Society for Endocrinology Published by Bioscientifica Ltd. Printed in Great Britain 

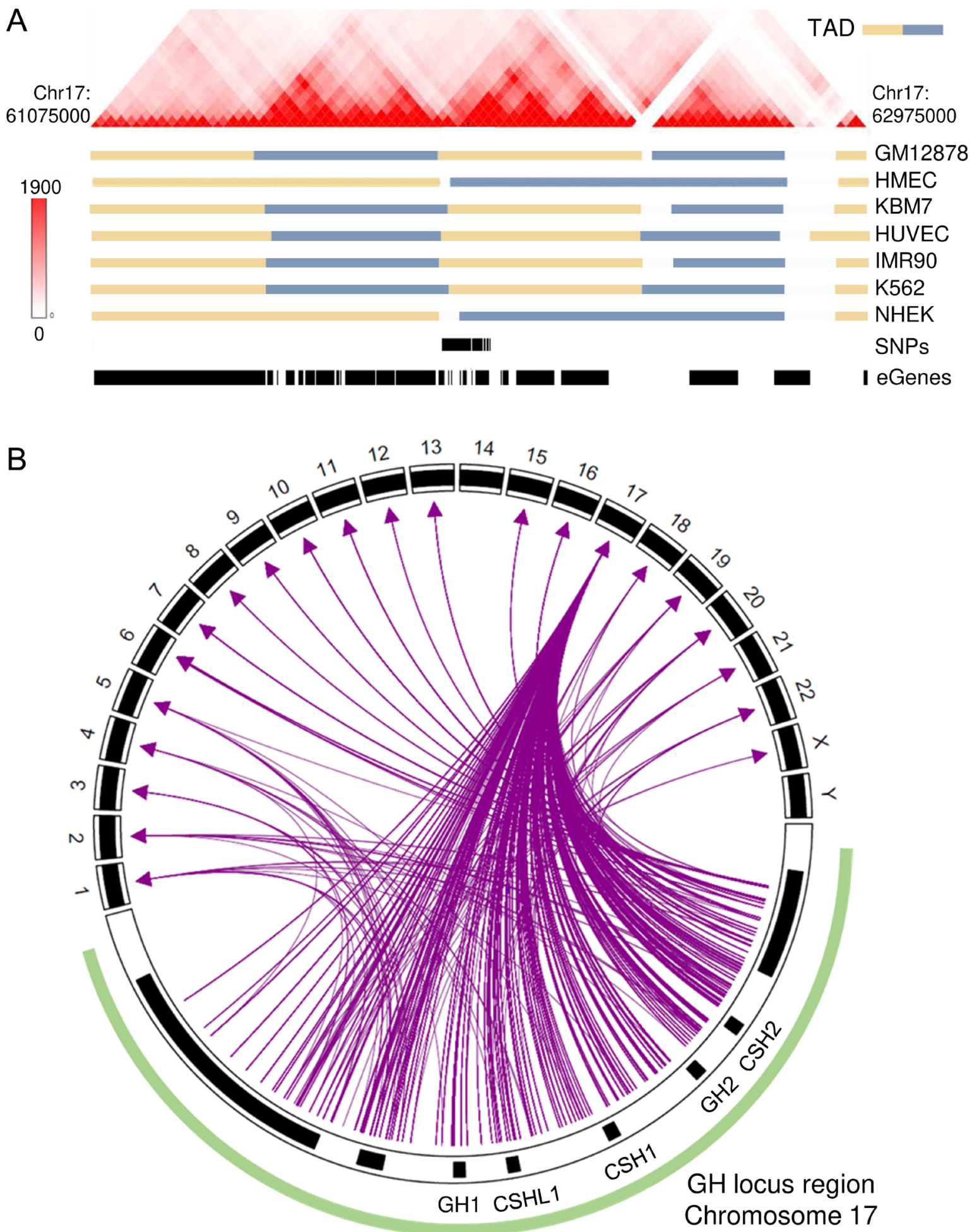

Figure 2

(A) Distribution of topologically associating domain (TAD) structures with (A) cis-eGenes (i.e. eGenes located $<1 \mathrm{Mb}$ from the SNP). The Hi-C heat map was generated with the 3D Genome Browser using data from Rao et al. (2014) for all the seven cell lines (GM12878, HMEC, KBM7, HUVEC, IMR90, K562 and NHEK). Tracks show TAD structures, the region containing the SNPs and identified eGenes. Blue and yellow bars represent different TAD regions. (B) A circus plot illustrating all the connections from GH locus SNPs to genes present on different chromosomes which includes chromosome 17. These eQTLs were not just limited to chromosome 17 but extended to multiple chromosomes. The circus plot has been split into two sections with the green curve representing the GH locus region across which the SNPs were analysed. 


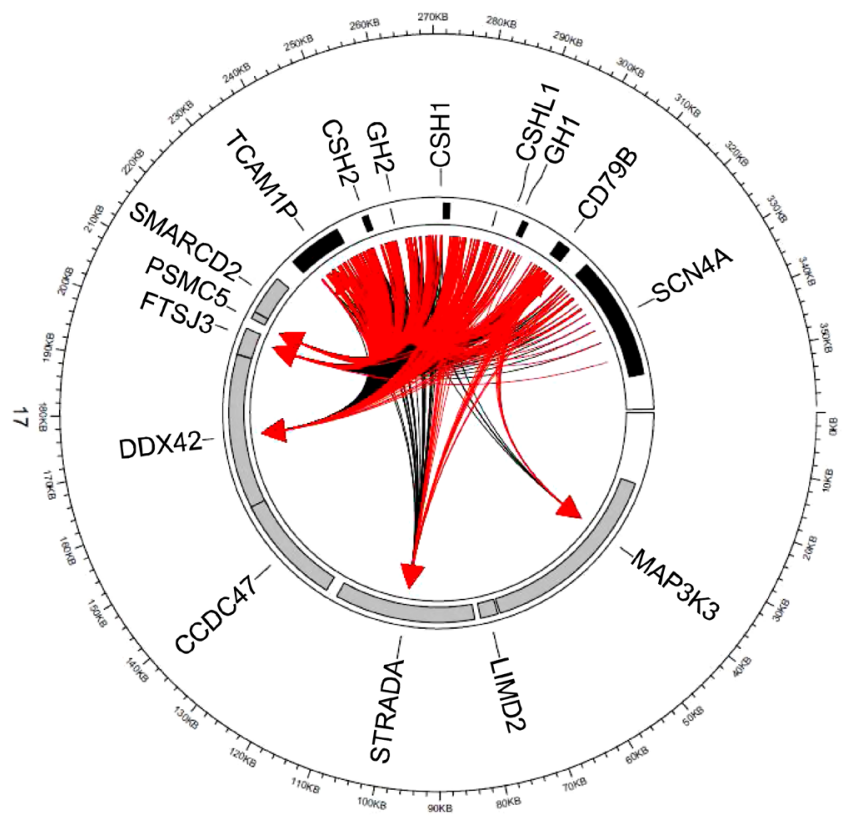

Pattern A

Example- Adipose visceral omentum

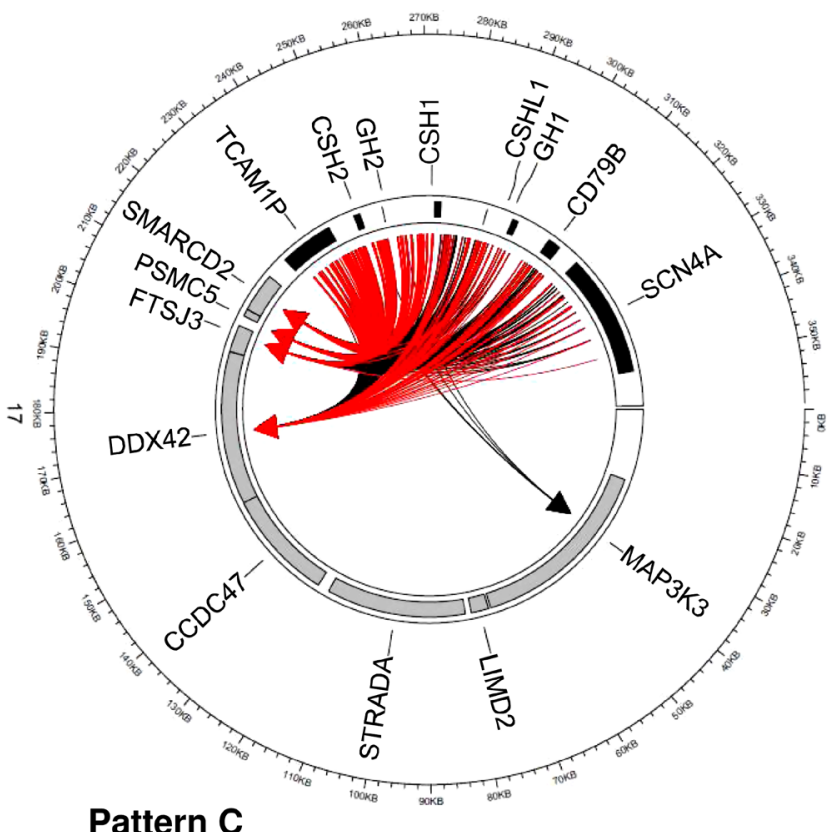

Example- Muscle skeletal

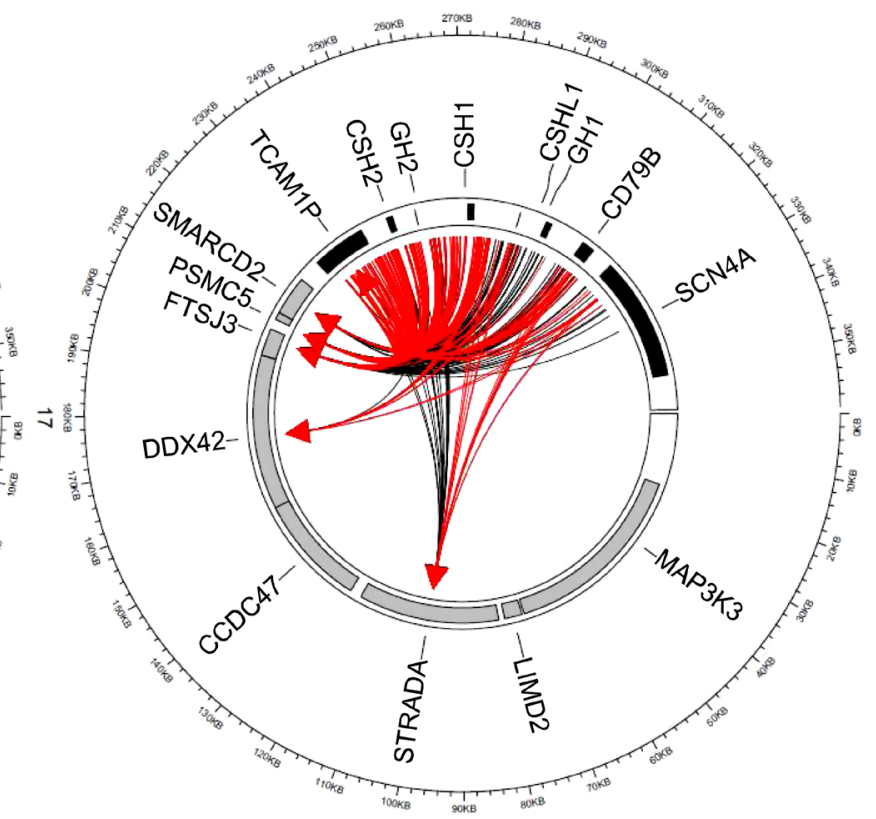

Pattern B

Example- Brain cortex

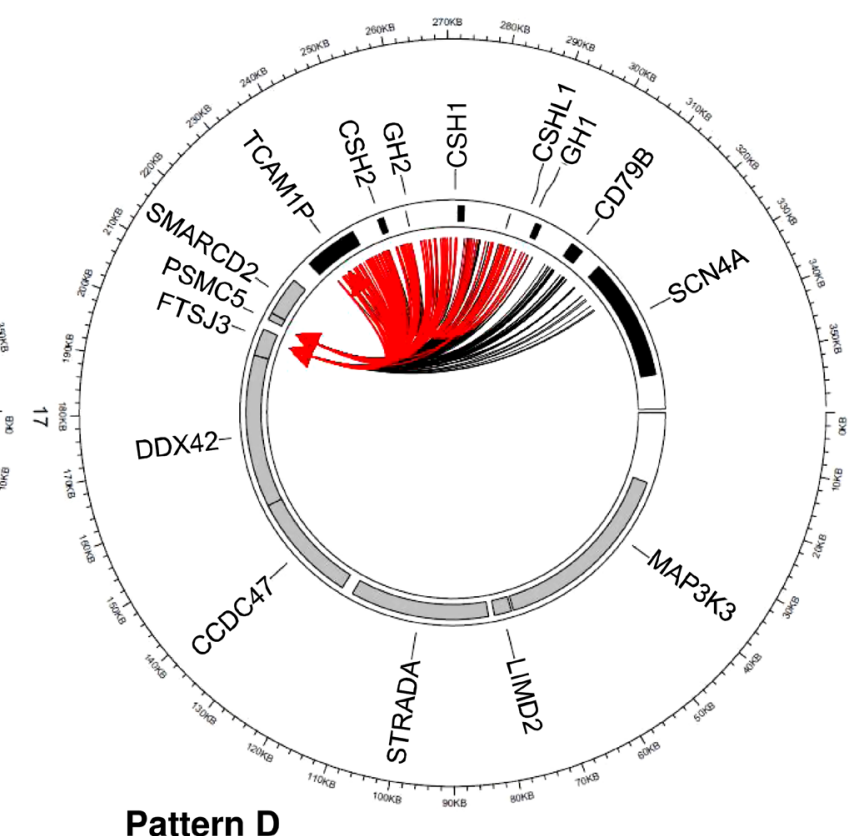

Example- Colon transverse

\section{Figure 3}

Pattern of cis-eQTL connections in different tissues. Identified contacts with genes present in the local environment of the GH gene locus appear to cluster together in four different pattern types as shown in the figure. Representative figures for patterns A, B, C and D are the connections observed in omental visceral adipose, cortex, skeletal muscle and transverse colon, respectively. Rectangles in black represent the genes of $G H$ locus across which SNPs were analysed and those in grey are the associated cis-eGenes. Links in red represent upregulation of the eGene associated with the SNP, whereas the links in black represent downregulation.

the age, sex (65.8\% male, $68.5 \%$ above 50 yrs of age) and tissue distribution (i.e. no placental samples) that was used to characterise expression profiles within the GTEx database (Ardlie et al. 2015).
CD79B displays a very complex eQTL-pattern. Eight CD79B SNPs (rs1051684, rs12603821, rs1051688, rs12451467, rs2070776, rs2005132, rs2320125 and rs8077653) connect to 66 eGenes in 48 different tissues. 


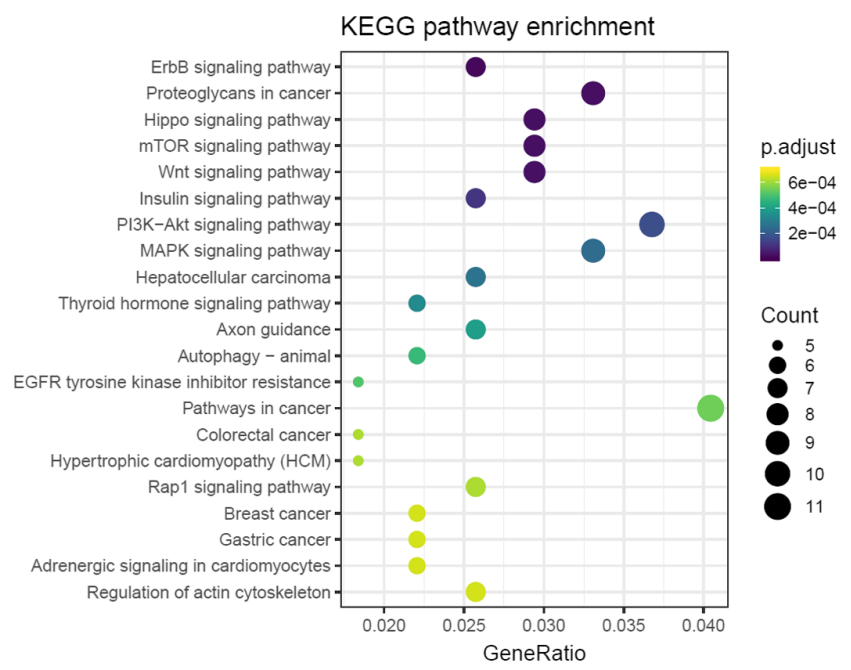

Figure 4

Dot plot showing top 20 pathways enriched by KEGG using g:Profiler. The plot is presented in decreasing order of adjusted $P$ value. The size of the circle represents the number of genes enriched in the pathways.

Out of these genes, 47 eGene contacts were in trans $(>1$ $\mathrm{Mb}$ away, distal) and 19 were in cis ( $<1 \mathrm{Mb}$ away, nearby). Out of 47 trans eGenes, 24 genes were distal but present on chromosome 17 (up to $59 \mathrm{Mb}$ downstream and 18 $\mathrm{Mb}$ upstream from $C D 79 B$ ). These eight SNPs were also associated with increased expression of the $C D 79 B$ gene in 11 tissues and a decrease in $C D 79 B$ expression in atrial appendage of the heart. Seventy-three output SNPs from across the analysed region were found to be associated with altered $C D 79 B$ expression in 16 tissues. Some of these SNPs were linked to an increase in expression of $C D 79 B$, whereas some were linked to the downregulation of this gene in a tissue-specific manner. This differential expression across tissues could imply disruption of binding sites of tissue-specific transcription factors by these or linked SNPs. For example, rs3815358 and rs12452767 occur in a CTCF binding site. CTCF is an important transcriptional regulator protein (Splinter et al. 2006).
Disruption of these CTCF binding sites can block or cause inefficient binding of transcription factors or may impact on other regulatory processes (Ohlsson et al. 2001).

To assess the cis connections with the GH locus SNPs, we investigated eQTLs with genes immediately downstream of the GH locus- SMARCD2, PSMC5, FTSJ3, DDX42, CCDC47, STRADA, LIMD2 and MAP3K3. We observed four strikingly different normalised effect size (NES) patterns in eQTL associations involving these genes across all the tissues (Fig. 3). Eleven tissues were classified as pattern $\mathrm{A}$, twelve as pattern $\mathrm{B}$, four as pattern $\mathrm{C}$ and fifteen as pattern D. It was interesting to observe such a marked difference between these patterns; however, the functional significance of these differences remains to be determined. Collectively, our results are consistent with the presence of regulatory sites located within the GH locus.

\section{Regions in the $G H$ locus interact with multiple genes (cis and trans) in a tissue-specific manner}

Within the GH locus, CSH2 exhibited the maximum number of associations with 114 SNPs in three tissues testis, brain cerebellum and brain cerebellar hemisphere. In addition, the ICAM2 and FTS/3 genes associated with 108 SNPs in one tissue (skeletal muscle) and 103 SNPs across all 48 tissues, respectively (Supplementary data 1-c). CSH2 is part of the $G H$ locus and has a high sequence similarity with other $G H$ genes.

While the cis-eGenes mostly had eQTLs with multiple SNPs in several tissues, trans-eGenes exhibited more tissuespecificity (Supplementary data 1-d.1). One hundred and thirty-nine eGenes formed an eQTL with only one SNP, whereas 55 had associations with two SNPs. Conversely, seven genes (SCPEP1, B3GNTL1, NCOR1, RGS9, VMP1, LINC00511 and CACNG4) had eQTLS with multiple SNPs (Supplementary data 1-d.2). For example, CACNG4

Table 2 Subset of identified SNPs in the GWAS catalogue.

\begin{tabular}{|c|c|c|c|}
\hline SNPs & Pubmed ID & Disease/trait & Sample size \\
\hline rs2005172 & 30593698 & Fat-free mass & $\begin{array}{l}\text { 70,700 European ancestry female } \\
\text { individuals and 85,261 European ancestry } \\
\text { male individuals }\end{array}$ \\
\hline rs2070776 & 20881960 & Height & 133,653 European ancestry individuals \\
\hline rs2070776 & 25282103 & Height & 253,288 European ancestry individuals \\
\hline rs 2532111 & 30595370 & Waist-hip ratio & $\begin{array}{l}\text { approximately } 458,000 \text { European ancestry } \\
\text { individuals }\end{array}$ \\
\hline rs28386778 & 28644415 & $\begin{array}{l}\text { Prudent dietary } \\
\text { pattern }\end{array}$ & 141 individuals \\
\hline rs2854160 & 25429064 & Height & 36,227 East Asian ancestry individuals \\
\hline rs2854160 & 21998595 & Height & 20,427 African ancestry individuals \\
\hline
\end{tabular}

\begin{tabular}{|c|c|}
\hline Context & $P$ value \\
\hline Intron variant & $8 \mathrm{E}-14$ \\
\hline Stop gained & 9E-09 \\
\hline Stop gained & $6 \mathrm{E}-41$ \\
\hline 3 prime UTR variant & $6 \mathrm{E}-10$ \\
\hline Regulatory region variant & 0.000006 \\
\hline Intergenic variant & $2 \mathrm{E}-12$ \\
\hline Intergenic variant & $5 \mathrm{E}-08$ \\
\hline
\end{tabular}


(Calcium Voltage-Gated Channel Auxiliary Subunit Gamma 4) was found to be associated with 40 SNPs in the atrial appendage.

Interestingly, we observed differences in the proportions of cis and trans eQTLs in different tissues. For example, the pituitary, which had the highest number of cis-eQTLs compared to all the tissues, did not have the highest number of trans-eQTLs. Brain-related tissues had the most eQTL-associations in trans (Supplementary data 1-e), whereas the pituitary had the maximum number of eQTLs with genes in cis (Supplementary data 1-f). This is particularly notable considering the role of the pituitary in $G H$-related function.

Some SNPs such as rs3815358 are connected with multiple eGenes (27 eGenes) in a variety of tissues (37 tissues), whereas a few SNPs such as rs11869827 are only associated with one or two eGenes (Supplementary data 1-g and $\mathrm{h}$ ). The maximum number of eGenes which SNPs in our data were associated with was 27. More than 50\% of the SNPs exhibited eQTL associations in all 48 tissues, which could imply that these SNPs could potentially have a role in regulation of normal cell functioning (Supplementary data 1-i).

\section{Genes targeted by GH eQTLs are potentially involved in growth hormone functions}

To explore if the set of eGenes (Supplementary data 1-j) were enriched for specific signalling pathways, we analysed the eGene sets using g:Profiler (Raudvere et al. 2019) (Supplementary data 1-k and 1). The top 20 most significant (adjusted $P$ value) enriched pathways are summarised in Fig. 4. This analysis demonstrated enrichment for a subset of these genes in numerous GH-related cellular signalling pathways such as the PI3K-AKT, MAPK, mTOR, prolactin, insulin and ERBB signalling pathways (Supplementary data $1-\mathrm{k}$ and 1 ). Another pathway which is potentially involved in regulation of $\mathrm{GH}$ signalling is the Wnt pathway, which was also among the enriched pathways (Supplementary data 1-m). There was also a significant representation of these genes in carcinogenic pathways. Five cancer terms were enriched in the KEGG subset and seven in the WikiPathways subset. There were four cancer types in common in both sets; these were hepatocellular carcinoma, colorectal cancer, breast cancer and non-small cell lung carcinoma. Altered GH signalling has previously been established to be associated with multiple cancer states, including the ones we identified (Chhabra et al. 2011, Clayton et al. 2011, Perry et al. 2017). There was also eGene enrichment in other pathologic conditions as well, like Alzheimer's and Huntington's disease. Altogether, these observations are consistent with the hypothesis that genetic variation in the $G H$ locus is associated with modulation of $\mathrm{GH}$ function.

\section{Identified eQTLs co-localise with GWAS signals}

To determine if the eQTLs we identified are associated with a disease or a population, we cross-referenced our list of SNPs with the genome-wide association studies (GWAS) catalogue (Buniello et al. 2019) and found that five variants (rs2005172, rs2070776, rs2532111, rs28386778 and rs2854160) exhibited GWAS associations with certain traits or populations (Table 2). rs2005172, rs2070776 and rs2532111 are associated with fat-free mass, height and waist-hip ratio, respectively, in individuals of European ancestry. SNP rs2854160 is associated with height in East Asian and African population, whereas rs28386778 is linked to prudent dietary patterns in 141 individuals. This is important in the context of GH biology, since regulation of height is one of the major functions modulated by this hormone. Excess or deficit in GH can lead to multiple growth disorders such as dwarfism, gigantism and acromegaly. SNP rs2070776, which is linked to height in European population, connects to 26 eGenes, (11 genes in cis and 15 in trans) across 39 different tissues. Six of the trans-eGenes are located on different chromosomes. One of these identified eGenes, NF1 (Neurofibromin 1), which is more than $1 \mathrm{Mb}$ distance away from rs2070776, is known to be strongly related to human height (KehrerSawatzki et al. 2017). The height-related SNP rs2854160 in individuals of East Asian and African descent connects to 13 eGenes in 42 tissues in which there are 11 cis-eGenes and two trans-eGenes (on the same chromosome). These two SNPs are located in different regions in the $G H$ locus.

\section{Regulatory potential of GH eQTLs are supported by functional studies}

We next sought experimental evidence for the SNP eQTL-eGene connections from published literature. van Arensbergen et al. recently developed a functional screening method known as Survey of Regulatory Elements (SuRE) which identifies SNPs that impact on regions of regulatory significance (van Arensbergen et al. 2019). Using this method, a total of 5.9 million SNPs were surveyed in two cell lines - human erythroleukemia cells (K562) and human hepatocellular carcinoma cells (HepG2) - to identify SNPs that alter the activity of putative regulatory elements (van Arensbergen et al. 2019). Thirty-three of the 
A

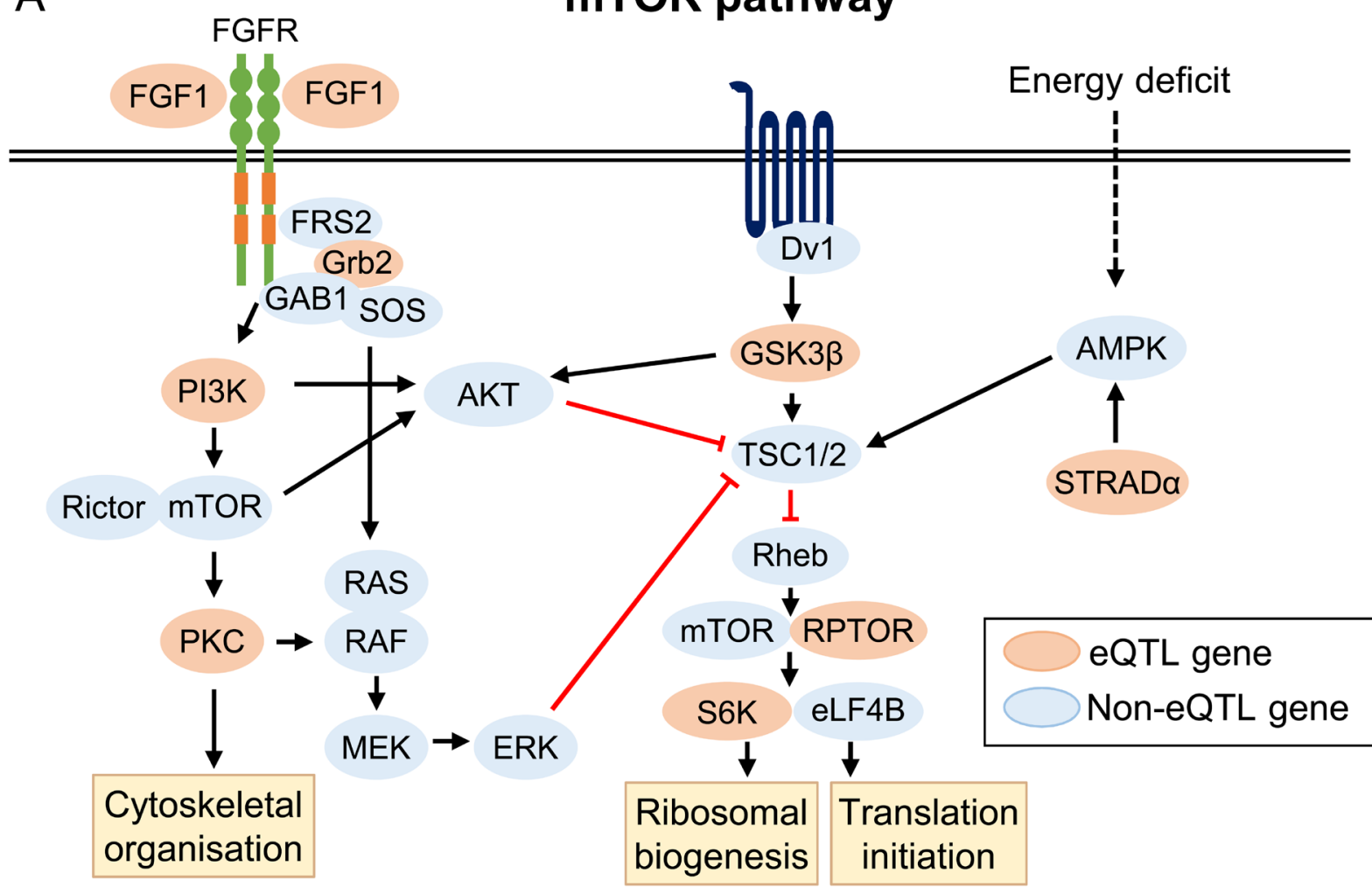

mTOR pathway

B

Wnt pathway

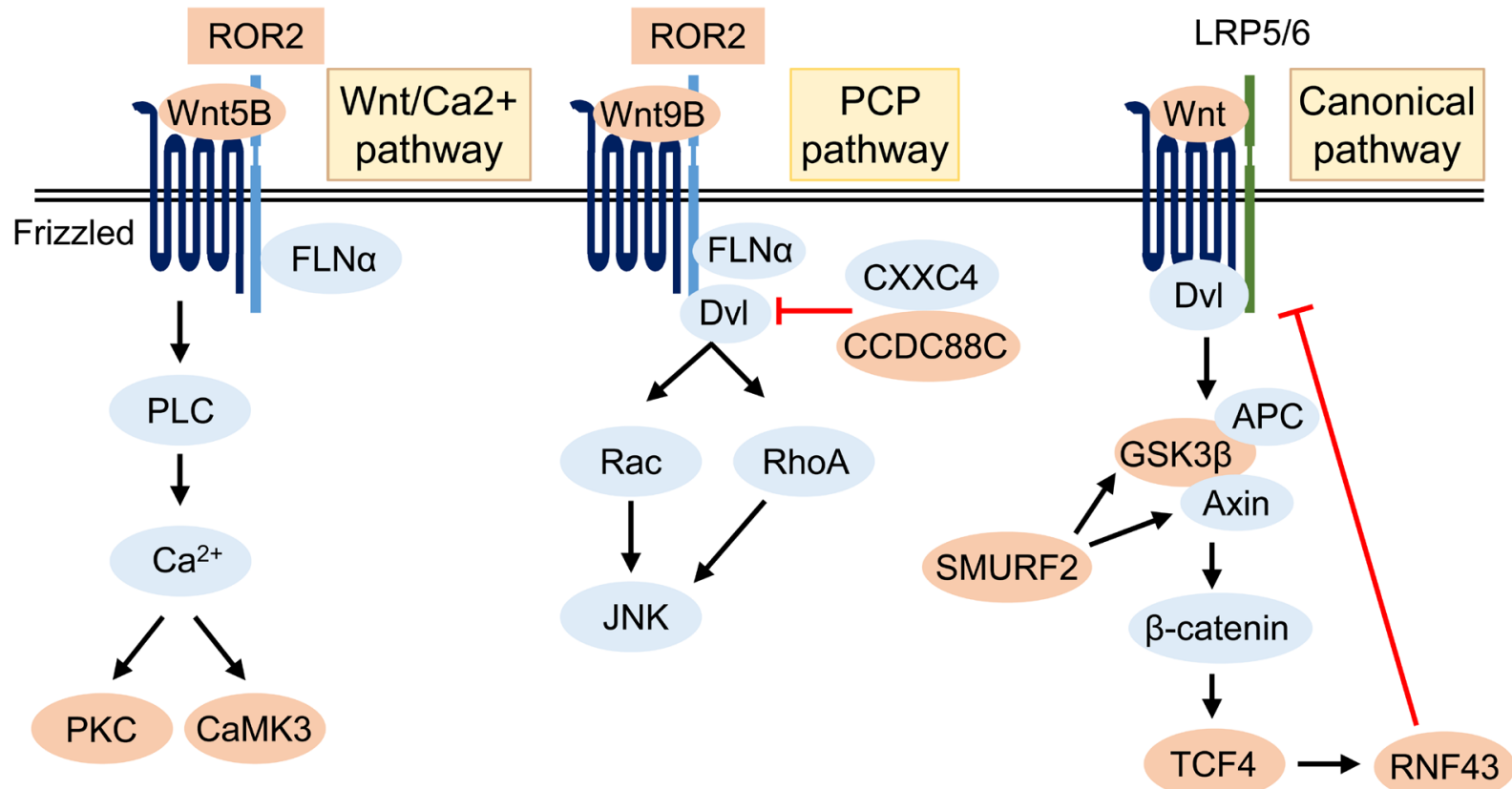

Figure 5

eGenes identified by CoDeS3D enriched in the MTOR (A) and Wnt (B) signalling pathways. These figures illustrate where these pathway-related eGenes fit in the cellular signalling cascade. Genes/proteins in orange boxes represent eQTL pathway-related genes, whereas those in blue boxes are non-eQTL genes. The eGenes and tissues in which these eQTLs were identified and the SNPs in which they connected to are summarised in Supplementary data $1-r$ and $q$. 
SNPs identified in our study were demonstrated to be of regulatory importance by van Arensbergen et al. Sixteen SNPs were identified in HepG2 cells and 16 in K562 cells, whereas one SNP, rs12451467, was found to be significant both cell lines (Supplementary data 1-n). Notably, our results also revealed Hi-C interactions between 17 SNPs with eGenes in K562. For example, SNP rs2584608 has regulatory interactions with 12 eGenes (including the chromatin-remodelling factor SMARCD2 and papillary thyroid carcinoma biomarker LIMD2), across 48 different tissues (Supplementary data 1-o).

To further strengthen the functional application of our approach, we analysed known enhancer/promoter regions using data retrieved from GeneHancer. There were 16 enhancer/promoter regions in the region used for our study (Chr17:62080000-61920000; GRCh37/hg19) which target 13 of the identified eGenes (Supplementary data 1-p). These regulatory regions encompass seven of the output SNPs (rs12452767, rs2286564, rs2286565, rs2457681, rs2665808, rs2854184, rs34684062, rs3815358, rs6171 and rs8080613), out of which two SNPs (rs2286564, rs2286565) were shown to have functional regulatory relevance in the data shown (Supplementary data 1-n). Collectively, these observations provide support for the functional roles of the eQTLs identified in this study.

\section{Discussion}

We analysed common SNPs within the $G H$ locus and identified it as a potential regulatory hub for genes located not only on chromosome 17 but also on other chromosomes. Many of the identified genes are a part of GH-related cellular signalling pathways including pathways in cancer. These results suggest that some GH functions could potentially be mediated by interaction of regulatory regions within the $\mathrm{GH}$ locus region.

When we examined the specifics of these eQTL-eGene interactions, we observed interesting gene expression patterns in a distinct tissue-specific manner. One hundred and fourteen SNPs from the entire $G H$ region were found to be associated with altered regulation of gene expression of $\mathrm{CSH} 2$ gene in the testis and brain tissues (cerebellar hemisphere and cerebellum). It should be noted that samples named brain cerebellum and brain cerebellar hemisphere in GTEx are considered duplicates, as they were the same tissue taken at different times postmortem (Ardlie et al. 2015). The presence of the eQTL in both indicates that the mRNA was not subject to rapid degradation due to senescence. Most of the $\mathrm{CSH} 2$ associated eQTL SNPs were found clustered just downstream of $\mathrm{CSH} 2$ gene. Although CSH2 mRNA expression is extremely low in the testis and brain (GTEx), CSH2 protein expression is observed in some germ cell tumours of the testis (Berger et al. 1999). CSH2 has also been linked to foetal growth disorders. pre-eclampsia and choriocarcinoma (Kim 2003, Männik et al. 2010, Liu et al. 2011).

$C D 79 B$ is an immune-related gene which is important for initialising signal transduction activated by the B-cell receptor complex (Alfarano et al. 1999). Polymorphisms in this gene have been linked to several types of cancer. Mutations in $C D 79 B$ have been linked to different types of diffuse large B-cell lymphoma (DLBCL) (Frick et al. 2018, Schrader et al. 2018) and to osteosarcoma (Mirabello et al. 2011). Identified SNPs in CD79B and CSH2 have enhancer marks in multiple human tissues and cell-lines. Analysis of known regulatory regions from GeneHancer showed that GH17J063930 is an enhancer for both CD79B and CSH2 and GH17J063877 is an enhancer for $\mathrm{CSH} 2$. This super-enhancer region encompasses four SNPs (rs2286564, rs2286565, rs3815358 and rs12452767), and the CSH2 enhancer overlaps with one SNP, rs2457681. Consistent with this, all four SNPs had eQTLs with $C D 79 B$ and $\mathrm{CSH} 2$ in our analysis and rs2457681 connected with CSH2 (Supplementary data 1-b). The study by van Arensbergen et al., which validated SNPs important for regulatory activities, identified two of the SNPs from this enhancer region (rs2286564 and rs2286565) as variants which are of regulatory importance (van Arensbergen et al. 2019). This is consistent with our hypothesis that the entire $G H$ locus potentially serves as a complex regulatory region.

Pathway analysis (g:Profiler) of the identified eGenes (292 genes) identified enrichment of these genes in various cellular signalling pathways, including classical GH-related pathways such as the PI3K-AKT, mTOR, MAP kinase, prolactin and insulin signalling pathways. The role of mTOR signalling in growth and development and mediation of GH function is well-established. mTOR is a protein kinase that regulates cell metabolism, proliferation and survival and is important for mediating GH-related pathways, including those related to insulin and IGF actions (Hayashi \& Proud 2007, Bartke 2011, Saxton \& Sabatini 2017), so it was interesting to find that eGenes associated with SNPs from the locus were enriched in the mTOR pathway (Fig. 5A; Supplementary data 1-q). Another pathway enriched in this analysis was the Wnt signalling cascade, which mediates embryonic development pathways, cell polarity, migration and division (Fig. 5B; Supplementary data 1-r). The enriched eGenes were part of both canonical and non-canonical Wnt signalling, 
as there is significant crosstalk between Wnt and other signalling pathways like mTOR, MAP kinase and P13K, it is possible that there was just an overlap between GH-mediated signalling and the Wnt pathway. However, several studies suggest a potential connection between $\mathrm{GH}$ and Wnt signalling (Vouyovitch et al. 2016, Osmundsen et al. 2017). For example, Vouyovitch et al. demonstrated that GH regulates the expression of the secreted protein Wnt4, a Frizzled receptor ligand (Vouyovitch et al. 2016). Therefore, we contend that GH may mediate some of its functions through direct impact on gene expression levels of the Wnt signalling cascade components, and this may be mediated by spatial interaction of these regions with the $G H$ locus. To confirm this, putative regulatory regions can be confirmed with reporter assays, and single-nucleotide editing techniques such as CRISPR/Cas coupled with proximity ligation assays like $\mathrm{Hi}-\mathrm{C}$ and gene expression studies may substantiate the impact of allele variants on the expression of Hi-C linked genes in vitro or in animal models. However, studies of this nature are complex, as regulatory regions often act in a combinatorial manner and, therefore, modification of isolated SNPs may have minimal impact.

Pathway enrichment analysis identified that eGenes associated with $G H$ locus SNPs were overrepresented in pathological conditions such as cancer, growth disorders and Alzheimer's disease. There is extensive literature supporting a role for GH in cancer. Altered GH signalling and increased expression of $G H$ and IGF-1 is linked to progression of numerous cancer types (Perry et al. 2013, Simpson et al. 2017, Lu et al. 2019). Autocrine GH increases the size of hepatocellular tumour xenografts and is associated with a worse relapse-free and overall survival in patients with hepatocellular carcinoma (Kong et al. 2016). GH decreases expression of the tumour suppressor gene $p 53$ in the colon and contributes to the development of colorectal carcinoma (Chesnokova et al. 2016). Elevated $\mathrm{GH}$ expression is also observed in colorectal cancer and is positively associated with tumour size and lymph node metastasis (Wang et al. 2017). Similarly, there are multiple studies which have established the key role of GH in breast cancer, endometrial and non-small cell lung carcinoma (Pandey et al. 2008, Chhabra et al. 2011, 2018, Perry et al. 2013, Lu et al. 2019). Identified eGenes in our data show significant enrichment in all of these cancer types, which suggests that the eGene set is strongly associated to GH-related cancer types, not purely by chance. This data suggests that genes in and around $G H$ locus and those associated with polymorphisms across the locus have a direct or indirect association with cancer, possibly by alteration of gene regulatory networks.

We also found an overlap between recent studies which identified genes associated with Alzheimer's disease and the eGenes in our data. There were five genes ( $A C E$, PRKCA, ERN1, GSK3B and MAPT) from one study (Grimm et al. 2019) and two genes from another (KRTAP5-AS and PSMC5) (Kikuchi et al. 2019) which were shared with the identified eGene set. This could possibly indicate a link between $G H$ gene locus mediated/coordinated gene regulation and Alzheimer's disease. However, significant experimental evidence is needed to substantiate this.

We show that there is a physical contact between SNPs across the $G H$ locus (including the locus control region) and GH2 and CSHL1 genes. In addition, we identify an association of these SNPs with change in expression levels GH2 and CSHL1 in pituitary tissue. This result can be linked back to studies from the Liebhaber and Cooke laboratories (Kimura et al. 2007, Ho et al. 2008, Tsai et al. 2016), which show that genes of the GH locus (GH1, GH2, CSH1, CSH2 and CSHL1) are expressed in the placenta or pituitary in a tissue-specific manner and are coordinated by the locus control region overlapping genes $C D 79 B$ and $S C N 4 A$. This regulation is under epigenetic control and is affected by chromatin looping that brings these regions into close proximity with the target promoters.

GH is crucial for modulation of normal growth and metabolism in the human body, through stimulation of signalling pathways and regulation of multiple growth factors. It is well-established that GH-related downstream pathways, such as mTOR, and other pathways identified here, such as Wnt signalling, are also pivotal in central biological roles affecting growth, development and metabolism (Taciak et al. 2018, Liu \& Sabatini 2020). The impact of GH on critical signalling cascades and their associated functions is likely a consequence of the interplay of genetic, molecular and evolutionary factors. Collectively, our observations support the hypothesis that the $G H$ locus (which includes GH1, GH2, and CSH1, CSH2 and CSHL1 and its locus control region spanning genes $C D 79 B$ and SCN4) functions as an extended regulatory region that coordinates expression of genes located both within and outside of the locus, which are in key GH-linked pathways and contribute to GH function. This is particularly important to consider in the context of evolutionary biology, as it is unlikely that co-regulation of these pathways has evolved by chance. Instead, it is consistent with the premise that genetic regions that are critical in coordinated regulation of aligned biological 
processes are linked as part of their maintenance. In the context of the human $G H$ locus, it is notable that most non-primate mammals only have a single $G H$ gene and that the $G H$ cluster arose from gene duplication independently in New World and Old World monkeys and thus varies considerably in structure (González Alvarez et al. 2006, Wallis \& Wallis 2006). Comparative studies of the $3 \mathrm{D}$ interactions between the $G H$ locus of primate and non-primate mammals with genes in pathways identified in our study may highlight the evolutionary significance of the co-regulation of these pathways.

\section{Supplementary materials}

This is linked to the online version of the paper at https://doi.org/10.1530/ JME-20-0010.

\section{Declaration of interest}

The authors declare that there is no conflict of interest that could be perceived as prejudicing the impartiality of the research reported.

\section{Funding}

J P, J O S, M V and L J were funded by a University of Auckland FRDF grant (3714499).

\section{References}

Alfarano A, Indraccolo S, Circosta P, Minuzzo S, Vallario A, Zamarchi R, Fregonese A, Calderazzo F, Faldella A, Aragno M, et al. 1999 An alternatively spliced form of CD79b gene may account for altered B-cell receptor expression in B-chronic lymphocytic leukemia. Blood 93 2327-2335. (https://doi.org/10.1182/blood. v93.7.2327.407a08_2327_2335)

Ardlie KG, Deluca DS, Segrè AV, Sullivan TJ, Young TR, Gelfand ET, Trowbridge CA, Maller JB, Tukiainen T, Lek M, et al. 2015 Human genomics. The genotype-tissue expression (GTEx) pilot analysis: multitissue gene regulation in humans. Science 348 648-660. (https://doi.org/10.1126/science.1262110)

Bache SM \& Wickham H 2016 magrittr: a forward-pipe operator for R. 12. (https://CRAN.R-project.org/package=magrittr)

Bartke A 2011 Growth hormone, insulin and aging: the benefits of endocrine defects. Experimental Gerontology 46 108-111. (https://doi. org/10.1016/j.exger.2010.08.020)

Berger P, Untergasser G, Hermann M, Hittmair A, Madersbacher S \& Dirnhofer S 1999 The testis-specific expression pattern of the growth hormone/placental lactogen (GH/PL) gene cluster changes with malignancy. Human Pathology 30 1201-1206. (https://doi. org/10.1016/S0046-8177(99)90038-2)

Bonert VS \& Melmed S 2017 Growth hormone. In The Pituitary, 4th ed. pp. 85-127. Elsevier. (https://doi.org/10.1016/B978-0-12-8041697.00004-0)

Brittain AL, Basu R, Qian Y \& Kopchick JJ 2017 Growth hormone and the epithelial-to-mesenchymal transition. Journal of Clinical Endocrinology and Metabolism 102 3662-3673. (https://doi. org/10.1210/jc.2017-01000)

Buniello A, Macarthur JAL, Cerezo M, Harris LW, Hayhurst J, Malangone C, McMahon A, Morales J, Mountjoy E, Sollis E, et al. 2019 The NHGRI-EBI GWAS catalog of published genome-wide

C) 2020 Society for Endocrinology Published by Bioscientifica Ltd. Printed in Great Britain association studies, targeted arrays and summary statistics 2019. Nucleic Acids Research 47 D1005-D1012. (https://doi.org/10.1093/ nar/gky1120)

Carter-Su C, Schwartz J \& Argetsinger LS 2016 Growth hormone signaling pathways. Growth Hormone and IGF Research 28 11-15. (https://doi.org/10.1016/j.ghir.2015.09.002)

Chen H, Levo M, Barinov L, Fujioka M, Jaynes JB \& Gregor T 2018 Dynamic interplay between enhancer-promoter topology and gene activity. Nature Genetics 50 1296-1303. (https://doi.org/10.1038/ s41588-018-0175-z)

Chesnokova V, Zonis S, Zhou C, Recouvreux MV, Ben-Shlomo A, Araki T, Barrett R, Workman M, Wawrowsky K, Ljubimov VA, et al. 2016 Growth hormone is permissive for neoplastic colon growth. PNAS 113 E3250-E3259. (https://doi.org/10.1073/pnas.1600561113)

Chhabra Y, Waters MJ \& Brooks AJ 2011 Role of the growth hormoneIGF-1 axis in cancer. Expert Review of Endocrinology and Metabolism 6 71-84. (https://doi.org/10.1586/eem.10.73)

Chhabra Y, Wong HY, Nikolajsen LF, Steinocher H, Papadopulos A, Tunny KA, Meunier FA, Smith AG, Kragelund BB, Brooks AJ, et al. 2018 A growth hormone receptor SNP promotes lung cancer by impairment of SOCS2-mediated degradation. Oncogene 37 489-501. (https://doi.org/10.1038/onc.2017.352)

Ciabrelli F \& Cavalli G 2015 Chromatin-driven behavior of topologically associating domains. Journal of Molecular Biology 427 608-625. (https://doi.org/10.1016/j.jmb.2014.09.013)

Clasen BF, Poulsen MM, Escande C, Pedersen SB, Møller N, Chini EN, Jessen N \& Jørgensen JOL 2014 Growth hormone signaling in muscle and adipose tissue of obese human subjects: associations with measures of body composition and interaction with resveratrol treatment. Journal of Clinical Endocrinology and Metabolism 99 E2565-E2573. (https://doi.org/10.1210/jc.2014-2215)

Clayton PE, Banerjee I, Murray PG \& Renehan AG 2011 Growth hormone, the insulin-like growth factor axis, insulin and cancer risk. Nature Reviews: Endocrinology 7 11-24. (https://doi.org/10.1038/ nrendo.2010.171)

Dehkhoda F, Lee CMM, Medina J \& Brooks AJ 2018 The growth hormone receptor: mechanism of receptor activation, cell signaling, and physiological aspects. Frontiers in Endocrinology 9 35. (https://doi. org/10.3389/fendo.2018.00035)

Dekker J, Marti-Renom MA \& Mirny LA 2013 Exploring the threedimensional organization of genomes: interpreting chromatin interaction data. Nature Reviews: Genetics 14 390-403. (https://doi. org/10.1038/nrg3454)

Duan K, Ezzat S, Asa SL \& Mete O 2015 Pancreatic neuroendocrine tumors producing GHRH, GH, ghrelin, PTH, or PTHrP. In Pancreatic Neuroendocrine Neoplasms, pp. 125-139. Cham: Springer International Publishing. (https://doi.org/10.1007/978-3-319-17235-4_15)

Dunham I, Kundaje A, Aldred SF, Collins PJ, Davis CA, Doyle F, Epstein CB, Frietze S, Harrow J, Kaul R, et al. 2012 An integrated encyclopedia of DNA elements in the human genome. Nature $\mathbf{4 8 9}$ 57-74. (https://doi.org/10.1038/nature11247)

Eijsbouts CQ, Burren OS, Newcombe PJ \& Wallace C 2019 Fine mapping chromatin contacts in capture Hi-C data. BMC Genomics 2077. (https://doi.org/10.1186/s12864-018-5314-5)

Fadason T, Ekblad C, Ingram JR, Schierding WS \& O'Sullivan JM 2017 Physical interactions and expression quantitative traits loci identify regulatory connections for obesity and Type 2 diabetes associated SNPs. Frontiers in Genetics 8 150. (https://doi.org/10.3389/ fgene.2017.00150)

Fishilevich S, Nudel R, Rappaport N, Hadar R, Plaschkes I, Iny Stein T, Rosen N, Kohn A, Twik M, Safran M, et al. 2017 GeneHancer: genome-wide integration of enhancers and target genes in GeneCards. Database 2017 bax028. (https://doi.org/10.1093/ database/bax028)

Frick M, Bettstetter M, Bertz S, Schwarz-Furlan S, Hartmann A, Richter T, Lenze D, Hummel M, Dreyling M, Lenz G, et al. 2018 Mutational frequencies of CD79B and MYD88 vary greatly between primary 
testicular DLBCL and gastrointestinal DLBCL. Leukemia and Lymphoma 59 1260-1263. (https://doi.org/10.1080/10428194.2017.1 370546)

Gadelha MR, Kasuki L, Lim DST \& Fleseriu M 2019 Systemic complications of acromegaly and the impact of the current treatment landscape: an update. Endocrine Reviews 40 268-332. (https://doi.org/10.1210/er.2018-00115)

Ganguly E, Bock ME \& Cattini PA 2015 Expression of placental members of the human growth hormone gene family is increased in response to sequential inhibition of DNA methylation and histone deacetylation. BioResearch Open Access 4 446-456. (https://doi. org/10.1089/biores.2015.0036)

Gibcus JH \& Dekker J 2013 The hierarchy of the 3D genome. Molecular Cell 49 773-782. (https://doi.org/10.1016/j.molcel.2013.02.011)

Gómez-Rubio V 2017 ggplot2 - elegant graphics for data analysis (2nd edition) Journal of Statistical Software 77 3-5. (https://doi. org/10.18637/jss.v077.b02)

González Alvarez R, Revol de Mendoza A, Esquivel Escobedo D, Corrales Félix G, Rodríguez Sánchez I, González V, Dávila G, Cao Q, de Jong P, Fu YX, et al. 2006 Growth hormone locus expands and diverges after the separation of new and old world monkeys. Gene 380 38-45. (https://doi.org/10.1016/j.gene.2006.05.017)

Grimm MOW, Lauer AA, Grösgen S, Thiel A, Lehmann J, Winkler J, Janitschke D, Herr C, Beisswenger C, Bals R, et al. 2019 Profiling of Alzheimer's disease related genes in mild to moderate vitamin D hypovitaminosis. Journal of Nutritional Biochemistry 67 123-137. (https://doi.org/10.1016/j.jnutbio.2019.01.015)

Gu Z, Gu L, Eils R, Schlesner M \& Brors B 2014 Circlize implements and enhances circular visualization in R. Bioinformatics 30 2811-2812. (https://doi.org/10.1093/bioinformatics/btu393)

Guevara-Aguirre J, Guevara A, Palacios I, Pérez M, Prócel P \& Terán E 2018 GH and GHR signaling in human disease. Growth Hormone and IGF Research 38 34-38. (https://doi.org/10.1016/j.ghir.2017.12.006)

Hannon AM, Thompson CJ \& Sherlock M 2017 Diabetes in patients with acromegaly. Current Diabetes Reports 17 8. (https://doi. org/10.1007/s11892-017-0838-7)

Hayashi AA \& Proud CG 2007 The rapid activation of protein synthesis by growth hormone requires signaling through mTOR. American Journal of Physiology: Endocrinology and Metabolism 292 E1647-E1655. (https://doi.org/10.1152/ajpendo.00674.2006)

Ho Y, Tadevosyan A, Liebhaber SA \& Cooke NE 2008 The juxtaposition of a promoter with a locus control region transcriptional domain activates gene expression. EMBO Reports 9 891-898. (https://doi. org/10.1038/embor.2008.126)

Kehrer-Sawatzki H, Mautner VF \& Cooper DN 2017 Emerging genotypephenotype relationships in patients with large NF1 deletions. Human Genetics 136 349-376. (https://doi.org/10.1007/s00439-017-1766-y)

Kikuchi M, Hara N, Hasegawa M, Miyashita A, Kuwano R, Ikeuchi T \& Nakaya A 2019 Enhancer variants associated with Alzheimer's disease affect gene expression via chromatin looping. BMC Medical Genomics 12 128. (https://doi.org/10.1186/s12920-019-0574-8)

Kim SJ 2003 Placental site trophoblastic tumour. Best Practice and Research: Clinical Obstetrics and Gynaecology 17 969-984. (https://doi. org/10.1016/S1521-6934(03)00095-6)

Kimura AP, Sizova D, Handwerger S, Cooke NE \& Liebhaber SA 2007 Epigenetic activation of the human growth hormone gene cluster during placental cytotrophoblast differentiation. Molecular and Cellular Biology 27 6555-6568. (https://doi.org/10.1128/MCB.00273-07)

Kong S \& Zhang Y 2019 Deciphering Hi-C: from 3D genome to function. Cell Biology and Toxicology 35 15-32. (https://doi. org/10.1007/s10565-018-09456-2)

Kong X, Wu W, Yuan Y, Pandey V, Wu Z, Lu X, Zhang W, Chen Y, Wu M, Zhang M, et al. 2016 Human growth hormone and human prolactin function as autocrine/paracrine promoters of progression of hepatocellular carcinoma. Oncotarget 7 29465-29479. (https://doi. org/10.18632/oncotarget.8781)
Lanctôt C, Cheutin T, Cremer M, Cavalli G \& Cremer T 2007 Dynamic genome architecture in the nuclear space: regulation of gene expression in three dimensions. Nature Reviews: Genetics 8 104-115. (https://doi.org/10.1038/nrg2041)

Liao S, Vickers MH, Stanley JL, Baker PN \& Perry JK 2018 Human placental growth hormone variant in pathological pregnancies. Endocrinology 159 2186-2198. (https://doi.org/10.1210/en.201800037)

Lieberman-Aiden E, Van Berkum NL, Williams L, Imakaev M, Ragoczy T, Telling A, Amit I, Lajoie BR, Sabo PJ, Dorschner MO, et al. 2009 Comprehensive mapping of long-range interactions reveals folding principles of the human genome. Science 326 289-293. (https://doi org/10.1126/science.1181369)

Liu GY \& Sabatini DM 2020 mTOR at the nexus of nutrition, growth, ageing and disease. Nature Reviews: Molecular Cell Biology In press. (https://doi.org/10.1038/s41580-019-0199-y)

Liu C, Zhang N, Yu H, Chen Y, Liang Y, Deng H \& Zhang Z 2011 Proteomic analysis of human serum for Finding pathogenic factors and potential biomarkers in preeclampsia. Placenta 32 168-174. (https://doi.org/10.1016/j.placenta.2010.11.007)

Lizio M, Harshbarger J, Shimoji H, Severin J, Kasukawa T, Sahin S, Abugessaisa I, Fukuda S, Hori F, Ishikawa-Kato S, et al. 2015 Gateways to the FANTOM5 promoter level mammalian expression atlas. Genome Biology 16 22. (https://doi.org/10.1186/s13059-0140560-6)

Lu M, Flanagan JU, Langley RJ, Hay MP \& Perry JK 2019 Targeting growth hormone function: strategies and therapeutic applications. Signal Transduction and Targeted Therapy 4 3. (https://doi.org/10.1038/ s41392-019-0036-y)

Männik J, Vaas P, Rull K, Teesalu P, Rebane T \& Laan M 2010 Differential expression profile of growth hormone/chorionic somatomammotropin genes in placenta of small- and large-forgestational-age newborns. Journal of Clinical Endocrinology and Metabolism 95 2433-2442. (https://doi.org/10.1210/jc.2010-0023)

Mirabello L, Yu K, Berndt SI, Burdett L, Wang Z, Chowdhury S, Teshome K, Uzoka A, Hutchinson A, Grotmol T, et al. 2011 A comprehensive candidate gene approach identifies genetic variation associated with osteosarcoma. BMC Cancer 11 209. (https://doi. org/10.1186/1471-2407-11-209)

Ohlsson R, Renkawitz R \& Lobanenkov V 2001 CTCF is a uniquely versatile transcription regulator linked to epigenetics and disease. Trends in Genetics 17 520-527. (https://doi.org/10.1016/S01689525(01)02366-6)

Osmundsen AM, Keisler JL, Mark Taketo MM \& Davis SW 2017 Canonical WNT signaling regulates the pituitary organizer and pituitary gland formation. Endocrinology 158 3339-3353. (https://doi. org/10.1210/en.2017-00581)

Pandey V, Perry JK, Mohankumar KM, Kong XJ, Liu SM, Wu ZS, Mitchell MD, Zhu T \& Lobie PE 2008 Autocrine human growth hormone stimulates oncogenicity of endometrial carcinoma cells. Endocrinology 149 3909-3919. (https://doi.org/10.1210/en.2008-0286)

Pekic S, Stojanovic M \& Popovic V 2017 Controversies in the risk of neoplasia in GH deficiency. Best Practice and Research: Clinical Endocrinology and Metabolism 31 35-47. (https://doi.org/10.1016/j. beem.2017.02.004)

Perry JK, Liu DX, Wu ZS, Zhu T \& Lobie PE 2013 Growth hormone and cancer: an update on progress. Current Opinion in Endocrinology, Diabetes, and Obesity 20 307-313. (https://doi.org/10.1097/ MED.0b013e328363183a)

Perry JK, Wu ZS, Mertani HC, Zhu T \& Lobie PE 2017 Tumour-derived human growth hormone as a therapeutic target in oncology. Trends in Endocrinology and Metabolism 28 587-596. (https://doi. org/10.1016/j.tem.2017.05.003)

Rao SSP, Huntley MH, Durand NC, Stamenova EK, Bochkov ID, Robinson JT, Sanborn AL, Machol I, Omer AD, Lander ES, et al. 2014 A 3D map of the human genome at kilobase resolution reveals 
principles of chromatin looping. Cell 159 1665-1680. (https://doi. org/10.1016/j.cell.2014.11.021)

. Raudvere U, Kolberg L, Kuzmin I, Arak T, Adler P, Peterson H \& Vilo J 2019 g:Profiler: a web server for functional enrichment analysis and conversions of gene lists (2019 update) Nucleic Acids Research $\mathbf{4 7}$ W191-W198. (https://doi.org/10.1093/nar/gkz369)

Rotwein P \& Chia DJ 2010 Gene regulation by growth hormone. Pediatric Nephrology 25 651-658. (https://doi.org/10.1007/s00467009-1258-y)

Sanyal A, Lajoie BR, Jain G \& Dekker J 2012 The long-range interaction landscape of gene promoters. Nature 489 109-113. (https://doi. org/10.1038/nature11279)

Saxton RA \& Sabatini DM 2017 MTOR signaling in growth, metabolism, and disease. Cell 168 960-976. (https://doi.org/10.1016/j. cell.2017.02.004)

Schierding W \& O'Sullivan JM 2015 Connecting SNPs in diabetes: a spatial analysis of meta-GWAS loci. Frontiers in Endocrinology 6102 (https://doi.org/10.3389/fendo.2015.00102)

Schierding W, Antony J, Cutfield WS, Horsfield JA \& O'Sullivan JM 2016 Intergenic GWAS SNPs are key components of the spatial and regulatory network for human growth. Human Molecular Genetics $\mathbf{2 5}$ 3372-3382. (https://doi.org/10.1093/hmg/ddw165)

Schrader AMR, Jansen PM, Willemze R, Vermeer MH, Cleton-Jansen AM, Somers SF, Veelken H, Van Eijk R, Kraan W, Kersten MJ, et al. 2018 High prevalence of MYD88 and CD79B mutations in intravascular large B-cell lymphoma. Blood 131 2086-2089. (https://doi. org/10.1182/blood-2017-12-822817)

Simpson A, Petnga W, Macaulay VM, Weyer-Czernilofsky U \& Bogenrieder T 2017 Insulin-like growth factor (IGF) pathway targeting in cancer: role of the IGF axis and opportunities for future combination studies. Targeted Oncology 12 571-597. (https://doi. org/10.1007/s11523-017-0514-5)

Splinter E, Heath H, Kooren J, Palstra RJ, Klous P, Grosveld F, Galjart N \& De Laat W 2006 CTCF mediates long-range chromatin looping and local histone modification in the $\beta$-globin locus. Genes and Development 20 2349-2354. (https://doi.org/10.1101/gad.399506)

Su Y, Liebhaber SA \& Cooke NE 1997 The human growth hormone locus control region supports pituitary- and placental-specific patterns of gene expression in transgenic mice. FASEB Journal 11 7902-7909. (https://doi.org/10.1074/jbc.275.11.7902)

Taciak B, Pruszynska I, Kiraga L, Bialasek M \& Krol M 2018 Wnt signaling pathway in development and cancer. Journal of Physiology and Pharmacology 69 185-196. (https://doi.org/10.26402/ jpp.2018.2.07)
Tang Z, Luo OJ, Li X, Zheng M, Zhu JJ, Szalaj P, Trzaskoma P, Magalska A, Wlodarczyk J, Ruszczycki B, et al. 2015 CTCF-mediated human 3D genome architecture reveals chromatin topology for transcription. Cell 163 1611-1627. (https://doi.org/10.1016/j. cell.2015.11.024)

Tarnawski AS, Ahluwalia A, Gergely HM \& Jones MK 2015800 Expression and co-localization of IGF-1, its receptor and survivin in esophageal progenitor cells: implications for esophageal mucosal renewal, protection and healing. Gastroenterology 148 S-157. (https:// doi.org/10.1016/S0016-5085(15)30529-1)

Tsai YC, Cooke NE \& Liebhaber SA 2016 Long-range looping of a locus control region drives tissue-specific chromatin packing within a multigene cluster. Nucleic Acids Research 44 4651-4664. (https://doi. org/10.1093/nar/gkw090)

Ulianov SV, Khrameeva EE, Gavrilov AA, Flyamer IM, Kos P, Mikhaleva EA, Penin AA, Logacheva MD, Imakaev MV, Chertovich A, et al. 2016 Active chromatin and transcription play a key role in chromosome partitioning into topologically associating domains. Genome Research 26 70-84. (https://doi.org/10.1101/gr.196006.115)

van Arensbergen J, Pagie L, FitzPatrick VD, de Haas M, Baltissen MP, Comoglio F, van der Weide RH, Teunissen H, Võsa U, Franke L, et al. 2019 High-throughput identification of human SNPs affecting regulatory element activity. Nature Genetics 51 1160-1169. (https:// doi.org/10.1038/s41588-019-0455-2)

Vouyovitch CM, Perry JK, Liu DX, Bezin L, Vilain E, Diaz JJ, Lobie PE \& Mertani HC 2016 WNT4 mediates the autocrine effects of growth hormone in mammary carcinoma cells. Endocrine-Related Cancer $\mathbf{2 3}$ 571-585. (https://doi.org/10.1530/ERC-15-0528)

Wallis OC \& Wallis M 2006 Evolution of growth hormone in primates: the GH gene clusters of the New World monkeys marmoset (Callithrix jacchus) and white-fronted capuchin (Cebus albifrons). Journal of Molecular Evolution 63 591-601. (https://doi.org/10.1007/ s00239-006-0039-5)

Wang JJ, Chong QY, Sun XB, You ML, Pandey V, Chen YJ, Zhuang QS, Liu DX, Ma L, Wu ZS, et al. 2017 Autocrine hGH stimulates oncogenicity, epithelial-mesenchymal transition and cancer stem cell-like behavior in human colorectal carcinoma. Oncotarget 8 103900-103918. (https://doi.org/10.18632/oncotarget.21812)

Waters MJ 2016 The growth hormone receptor. Growth Hormone and IGF Research 28 6-10. (https://doi.org/10.1016/j.ghir.2015.06.001)

Zerbino DR, Achuthan P, Akanni W, Amode MR, Barrell D, Bhai J, Billis K, Cummins C, Gall A, Girón CG, et al. 2018 Ensembl 2018. Nucleic Acids Research 46 D754-D761. (https://doi.org/10.1093/nar/ gkx1098)

Received in final form 17 february 2020

Accepted 27 February 2020

Accepted Manuscript published online 27 February 2020 (c) 2020 Society for Endocrinology Published by Bioscientifica Ltd. Printed in Great Britain 